\title{
Cultural Mobilities: Diversity and Agency in Urban Computing
}

\author{
Paul Dourish ${ }^{1}$, Ken Anderson ${ }^{2}$, and Dawn Nafus ${ }^{2}$ \\ ${ }^{1}$ Donald Bren School of Information and Computer Sciences \\ University of California, Irvine \\ Irvine, CA 92697-3440, USA \\ jpd@ics.uci.edu \\ ${ }^{2}$ People and Practices Research \\ Intel Corporation \\ 20270 NW AmberGlen Court \\ Beaverton, OR 97006, USA \\ ken.anderson@intel.com, dawn.nafus@intel.com
}

\begin{abstract}
The rise of wireless networks and portable computing devices has been accompanied by an increasing interest in technology and mobility, and in the urban environment as a site of interaction. However, most investigations have taken a relatively narrow view of urban mobility. In consequence, design practice runs the risk of privileging particular viewpoints, forms of mobility, and social groups. We are interested in a view of mobility that reaches beyond traditional assumptions about the who, when, why, and what of mobility. Based on analytic perspectives from the social sciences and on empirical fieldwork in a range of settings, we outline an alternative view of technology and mobility with both analytic and design implications.
\end{abstract}

\section{Introduction}

Computing is on the move. Mobile telephony, wireless networking, embedded computing and ubiquitous digital environments are manifestations of a broader pattern in which mobility plays an increasingly significant role in the computational experience. In turn, this mobilization of information technology has turned research attention towards the domains in which technology might now operate. One site of research attention has been "urban computing," investigating the ways in which information technologies shape, are shaped by, and mediate our experience of urban space. While this focus on urban settings runs the risk of furthering the traditional dominance of urban experience over the interests of suburban, exurban and rural settings, it reflects both the contemporary reality of the city as a nexus of computational infrastructures [28] and recent scholarly discussions of urbanism and information technologies, e.g. [22]. Interest in "urban computing" has appeared in papers in major conferences such as $\mathrm{CHI}$ and Ubicomp, and also been a topic for a number of recent journal special issues.

To date, though, while mobile devices have radically transformed and widely proliferated in recent years, mobile computing in the city has been construed quite 
narrowly. This narrowness concerns both the applications that urban computing explores and the ways in which it construes its users. On the application side, many systems design efforts focus on the city as a site of consumption and an inherently problematic environment, one to be tamed by the introduction of technology. On the user side, many systems design efforts focus their attention on young, affluent city residents, with both disposable income and discretionary mobility.

The narrowness of both the site and "the users," we will argue, has meant that mobile and urban computing have been driven by two primary considerations. The first is how to "mobilize" static applications, allowing people to get access to information and carry out traditional desktop tasks while "on the move," the anytime/anywhere approach as manifested in PDA applications that attempt to produce mobile versions of desktop applications or connect people wirelessly to remote infrastructures "back home" (e.g. email on the RIM Blackberry.) The second is how to provide people with access to resources in unfamiliar spaces, the "where am I?" approach, as manifested in context-aware applications that attempt to help people navigate space in terms of resource such as devices (e.g. the nearest printer), services (e.g. recommending stores), or people (e.g. finding friends via Dodgeball). While these applications clearly meet needs, they fail to take the urban environment on its own terms; they are based on the idea that urban life is inherently problematic, something to be overcome, in comparison to the conventional desktop computing scenario. Further, they fail to acknowledge the lived practice of urban life, and in particular its diversity and the different urban experiences of different groups. In focusing on abstracted rather than concrete behaviors, on individual consumption rather than collective sociality, and on the pairing between discretionary mobility and urban consumption, this approach paints a very partial view of urban living that leaves many people out of the picture.

Rather than simply attempting to move existing application scenarios to mobile platforms, our approach is to take a step back and begin by thinking about mobility more broadly, particularly in connection to urban space. To do so, we turn to research in social science that seeks to understand the relationship between meaning, identity, movement, and space, drawing particularly on work in anthropology and cultural geography. Based on theoretical and empirical work from social science, we are developing a new approach to the relationship between mobility and technology.

Our work is oriented around three interrelated principles:

Mobilities, not mobility: mobility takes many forms. Not only are there different kinds of journeys (commuting to work on public transit, flying to a vacation spot, moving house), but the same journeys can be undertaken under very different auspices (taking a train from home to the town center in order to go to work, in order to go out for the evening, in order to seek medical treatment, or because you're driving the train.) An understanding of the relationship between mobility and technology requires that we take a heterogeneous view of mobility, rather than focusing only on selected social groups and patterns of urban life.

Finding more than your way: movement is not purely a way to get from A to B. It extends beyond the purely instrumental and efficacious. Routes may have symbolic significance (pilgrimages, ritual exclusions to do with gender or caste, traditions and routes of historical importance), choices may be influenced by a personal aesthetics (the pleasure of a craftily-executed maneuver on the freeway, a response to the 
presence and absence of particular others on public transit, or an aimless stroll through the streets of an unfamiliar city), and patterns of movement may enact social and cultural meanings (undertaking the hajj, or participating in an Orange March in Northern Ireland.) Understanding mobility in its cultural settings requires that we pay attention to the symbolic and aesthetic aspects of technological urbanism as well as the purely instrumental.

Mobility as collective: the patterns and experience of movement are collective rather than individual experiences. Mobility is experienced through social and cultural lenses that give it meaning in historical, religious, ethnic, and other terms. We move individually but collectively we produce flows of people, capital, and activities that serve to structure and organize space. In seeing urban mobility as a social phenomenon, we want to look at the ways in which new technologies provide a site for creating new forms of collective practice and meaning.

Taken together, these principles open up the design space for urban computing, by seeing mobility in urban spaces not simply as problematic alternative to static activity, but rather as a culturally meaningful and productive phenomenon in its own right. Starting with the concept of mobility, rather than starting with technology, we can achieve a better link between people and technology. From this perspective, we start to see urban and mobile technologies less as tools for problem-solving and more as sites at which social and cultural practice are produced. In turn, this raises a new and different set of questions for the design, development, and deployment of socially responsible mobile technologies.

In what follows, we explore the basis of this alternative account of urban computing and its consequences, with a particular focus on the questions of socially responsible design. We begin by exploring the theoretical background, drawing on social science accounts of mobility and spatiality to support a perspective on mobile and urban computing that stresses diversity and agency. Next, we draw on ethnographic fieldwork to present accounts of urban living that illustrate our principles in real settings. Finally, we consider how this alternative account of mobility poses new challenges for interactive system design.

\section{Mobile Technologies and Urban Problems}

The current interest in urban computing springs not least from research conducted for over a decade into mobile computing and its applications. We identify four broad areas of research into mobility and mobile computing applications.

The first area comprises systems that frame mobility as a disconnection from stable working situations, and overcome this either by providing mobile, remote access to static information resources or by attempting to reproduce static application contexts. The classic application scenario here would involve a mobile worker such as a person on a business trip who needs information from the office back home. The Satchel system, for example, sought to provide people with easy access to electronic documents, including the ability to share and exchange them, by developing mobile digital tokens that could be used to manipulate documents stored centrally [27]. The resources to which a mobile person might need connected also include other people. For example, Hubbub [25] explores means to link mobile users into traditional 
messaging applications; and a series of studies at the University of Glasgow have investigated forms of "co-visiting" in which static and mobile participants interact around the same physical resources $[10,11]$. In this category, we also place attempts to replicate in mobile settings the sorts of applications that people might use in static or desktop settings.

Our second category of applications also sees mobility as problematic, but addresses its problems in different ways. These are applications that attempt to address the problem of dislocation by focusing on wayfinding and resource location. GPS navigation systems, either hand-held or installed in cars, are one obvious example, as are guides that attempt to help people find their way through an unfamiliar environment, including: tourist sites, e.g. [14]; academic conferences, e.g. [17]; museums, e.g. [23]; and university campuses, e.g. [13].

The third category focuses not on the problems of disconnection or dislocation but rather on the problems of disruption. Disruption problems are the ways in which a mobile technology might behave in ways inappropriate to the settings into which it is moved. Systems of this sort attempt to be sensitive to context or location so as to provide a customized service. For instance, the idea that a mobile telephone might set itself automatically to vibrate mode when in a theater, or might filter out low importance calls when in a meeting, are simple examples of context-sensitivity [2]. Other examples include health monitors that attempt to time their requests so as to minimize interruptions [24], and public displays that respond to the patterns of movement in spaces, e.g. [43]. We describe these systems as focused on disruption because they respond to a sense of rupture between the technology and the setting in which it is deployed.

Our fourth and final category is the most recent to emerge, and the most diverse. The applications that we label as "locative media" (a term coined by Vancouverbased artist Karlis Kalnins) see mobility not as a problem to be overcome but as offering certain interactional opportunities. These applications, which often emerge in artistic or entertainment contexts, seek to create interactive experiences that rely upon or exploit movement and space. For instance, the Equator project, an interdisciplinary university research consortium in the UK, has produced a series of mobile games that blend physical and virtual worlds in order to create new experiences of space and movement. Can You See Me Now [8], a game played on the streets of Sheffield, created a novel hybrid space in which participants "virtually" present would interact with those physically in the urban space; Treasure [3] encourages players to explore the "seams" in digital infrastructures as they are mapped into physical spaces (e.g. wireless network coverage) and to incorporate them into game play, while Yoshi [7] exploits similar mappings between physical and virtual, but on an urban scale. Reminiscent of studies of the urban soundscape [20], projects such as Sonic City [21] or tuna [5] explore the ways in which movement through space can create personal or collective audio experiences, giving a new (aural) form to movement. PDPal (www.pdpal.com), a project by Scott Patterson, Marina Zurkow, Julian Bleecker, and Adam Chapman, and originally co-commissioned by the Walker Art Center and the University of Minnesota Design Institute, encourages people to create and browse emotional maps of urban spaces, combining "objective" cartographic forms with more personal and intimate interpretations of the lived city. 
Often, these projects have a strong critical component, and indeed the theoretical positioning of much locative media practice appeal to Michel Foucault's [19] concept of "heterotopia" (an analysis of the relationship between space, power, and cultural practice), and on the Situationist movement in 1960's artistic avant garde. The Situationist perspective is related in two ways. First, their critique of the "society of the spectacle" [46] motivates a form of active engagement with the everyday life and its structures, and, second, Guy Debord's [16] theory of "the dérive" (essentially, a journey with no destination) as a means to re-encounter and re-appropriate urban spaces. So, projects such as "Riot! 1831" [42] or GPSdrawing (www.gpsdrawing.com), which uses GPS traces of movements through space to literally "draw" images on maps or photographs, build upon a range of location-based technologies to provoke new ways to think about movement and spatial practice in technology-mediated contexts.

The work under the "locative media" category is particularly intriguing because it opens up a new set of intellectual conversations around mobility and technology, and a new area of the design space. What we find particularly compelling about this fourth category of work is the way in which it frames mobility not as a problem but as both an everyday fact and a new opportunity. In addition, this critical component of some of this work forms part of a broader movement to explore new hybrid disciplinary practices that have tremendous value for the development of interactive media and applications, and this plays a role in the research that we plan to conduct. Where we want to extend this work is by situating it not only in artistic considerations but also in contemporary social science of space and movement.

What we have noted in these four approaches, then, is a transition from "mobility as problem" (the first three categories) to "mobility as opportunity" (the final category.) In making this transition, the developers of mobile and urban applications have begun to incorporate lessons from social science and, in particular, from contemporary work on human geography that looks at the ways in which people produce spatial experience. If urban computing is fundamentally a technology of space, then it seems appropriate to turn to those areas of research in which spatiality plays a central role. In order to deepen this connection between technology and geographical thinking, we turn next to the research literature that approaches the nexus of technology and urban spatiality form the spatial perspective rather than the technical.

\section{Social and Cultural Accounts of Mobility and Technology}

Increasingly, information technology plays a significant role in both spatial research and spatial practice, and geographers and social scientists have begun to incorporate accounts of information technology into their models of spatiality and spatial practice.

Graham [22] uses the term "software-sorted geographies" to point to the ways in which software systems increasingly act as the lenses through which we encounter the world, and, in turn, their logics become inscribed into those spaces. He organizes his account around three primary examples. The first is the role of information systems in organizing and regulating mobility, drawing from studies of air travel and intelligent transportation systems, where software systems regulate flows of people and goods 
through space at a variety of scales. The second is the use of geographical information systems and geodemographic systems as ways in which spaces and people are categorized, stratified, and understood, and incorporated into systems of planning and provision of services. The third is the use of CCTV and face-recognition software as a means of monitoring and controlling public spaces. In each case, the use of software systems as means of spatial ordering raises important questions of the ownership, control, and visibility of the software systems, as well as the representational categories and biases built into the systems (such as cultural assumptions encoded in face recognition software, or expectations about "normal" patterns of freeway or air travel.)

These kinds of representational schemes - the mechanisms by which people, places, and activities can be categorized, counted, and regulated - are, of course the traditional tools of state governance, and indeed the development of computers as administrative tools has long been associated with the systems of local and national governance [1]. Graham is concerned, then, with the spatial politics of software systems. Thrift and French [45] explore a similar set of concerns, although with a somewhat different emphasis. Like Graham, they are motivated by the ways in which spatial settings are increasingly ordered by software systems; but they are especially concerned with the metaphors that underlie those software systems, and the ways in which, through approaches to software design and production such as neural networks, adaptive architectures, and open source development methods, software systems model themselves on corporeal and social systems.

While Thrift and French acknowledge the ways in which software systems not only reflect institutional power dynamics but provide the opportunity to rescript them, they nonetheless focus their attention primarily on the production of software. So, for instance, they acknowledge the fact that the governmentality of software systems is perhaps more the "rhizomal," horizontal governmentality of Deleuze than the hierarchical governmentality of Foucault; the ways in which the development of spreadsheet software created new opportunities and new models for organizational decision-making and alignment; and the ways in which new media artists can produce software systems that challenge conventional models of interaction.

What is missing from this picture is an account of the ways in which software is not just produced, but put to use. Graham, Thrift, and French are right to point to the ways in which software is a tool for imposing an external regulative order upon space and movement, but we would argue that it is also a means by which new spatial experiences are produced. Indeed, software systems are sites of resistance as well as control, and aspects of how new spatial experiences are produced.

\section{An Alternative Framework}

What this provides is a very different way to think about the relationship between information technology and spatial experience, with implications both for analysis and design of mobile technologies. It looks at information technologies not simply as things that move between different places, but as means in which spatial structures are produced. Paying attention to these power structures, and in particular to what Massey [30] (discussed below) refers to as "power-geometries", highlights the diversity of 
mobile experience. While young, affluent city residents with a penchant for gadgets, disposable income and discretionary mobility have one sort of urban experience - one reflected in much of contemporary urban computing, one focused largely on the city as a site of consumption - others may be positioned very differently with respect to the circuits of urban movement and habitation. The geographical studies point to the important role of diversity in understanding the urban experience.

At the same time, as we have noted, we feel that one failing of some of these studies is the primacy that they give to technology as a tool of regulation and surveillance, in contrast to a site for creative engagement with space. Famously, De Certeau [15] describes two modes of spatializing, what he calls the strategic and the tactical. If the strategic mode is the mode of design and regulation, then the tactical mode is the mode of use and resistance. The people who enact spatial practice are not simply the designers, architects, planners, and regulative authorities; they are people who, through their everyday movements through urban space, give that space life and meaning. So, alongside the concert with diversity, we would like to place an equal emphasis on individual and collective agency.

This perspective suggests three important starting points for a study of technology and mobility.

\subsection{Mobilities, Not Mobility}

Contemporary interest in mobility as an aspect of life and work often gloss the diverse and specific forms that mobility may take. One might question whether a term that encompasses phenomena as diverse as transnational diasporas, daily commutes, and religious pilgrimages is doing useful conceptual work at all. Even within constrained settings, the notion of "mobility" may obscure as much as it reveals.

In a brief ethnographic study of riding public transit in Orange County [9], this diversity was very much in evidence. In place of a conventional image of working commutes, we found a much richer picture of movement and mobility at work. We encountered people who rode the bus for work and for pleasure, whose journeys were dead time to be endured or spiritual moments, who were on the bus to see people or to escape from them, whose goal was to get to hospital or pick up women, and who found themselves riders of public transit due to financial, family, health, or legal causes.

While the notion of mobility and technology conjures up the image of a jet-setting businessman armed with a laptop or a smart phone, able to carry out his work "anytime, any-where." The easy, discretionary mobility of the professional stands in marked contrast to the enforced movement of the homeless, for whom movement from place to place is the only way to avoid detention [44], or some transnationals who leave their children behind in a desperate search of economic opportunity, moving to cities that they must often navigate through and around as if they are invisible. Different again is the form of urban movement forced on the South African AIDS sufferers documented by le Marcis [29]. The "suffering body" of AIDS patients, on the other hand, must move - despite difficulties presented by ill health in an ever expanding network of clinics, hospitals, support groups and hospices, coming to rest finally in the graveyard. Both the necessity of and ability to travel are mediated by local political factors; the remnants of apartheid are reflected by the 
location and quality of hospitals, and the monthly disability check received by many AIDS sufferers exactly equals the cost of a month's worth of AZT. Due to the stigma still attached to the disease, people travel several hours to meet with HIV support groups because they would be recognized attending one in their own neighborhood.

If "mobility" encapsulates such heterogeneity, what of "mobile computing"? Designing "for mobility" must be, in fact, design for a host of different potential mobilities. Mobility is far from uniform, and the needs, problems, and opportunities that attend mobile computing are similarly diverse.

\subsection{Finding More Than Your Way}

In his study of identity issues in a Northern Irish town, William Kelleher [26] describes the ways in which sectarian identity is enmeshed into the spatial organization of the city. Residents describe the historical patterns of settlement and migration by which the contemporary urban social landscape was formed. Invisible fault lines criss-cross the city creating structures that give meaning to patterns of presence and movement. The sectarian organization of everyday life manifests itself in everything from forms of dress and speech to where one parks when in the town center. Navigation through urban space, then, enacts aspects of cultural identity. On a broader scale, Duruz's study of shopping streets in London and Sydney and the "culinary journeys" involved in shopping, eating, and living there point to the ways in which local spatial arrangements are products of broad historical patterns of movement and migration [18]. As Massey provocatively writes regarding her local high street, "It is (or ought to be) impossible even to begin thinking about Kilburn High Road without bringing into play half the world and a considerable amount of British imperialist history." [30:65]

We make sense of the spaces through which we move not simply in terms of their local geometries, but their positions in larger frames - be those historical frames as in the case invoked by Massey, mythological frames as in the case of Aboriginal landscapes described by Nancy Munn [40], moral frames as in the ties between moral lessons and the landscape for native Americans as described by Keith Basso [4], or sometimes all of these at once, as in Kelleher's Ballybogoin.

Wayfinding - either following a route or finding resources in an unfamiliar environment - has long been a domain of application for mobile technologies (e.g. $[14,17])$. However, a purely instrumental reading of space - as something to be navigated efficiently and exploited effectively - neglects these other social, cultural, moral, political and historical aspects of spatial and mobile experience. When people move through space, they must find their way, but they also find more than their way.

\subsection{Mobility as Collective}

Running through these principles is a third view of mobility as a collective rather than an individual phenomenon. We are concerned not so much with how specific people move from A to B, but rather with collective phenomena in two senses. The first is how repeated patterns of movement create larger spatial structures, and the second is how those structures then serve to make sense of particular mobilities. 
This is very much a relational view of mobility. When an individual undertakes a pilgrimage to a sacred site, the journey makes sense not purely in terms of an individual experience or in terms of the historical pattern of previous journeys, but in the relationship between the two; the journey's meaning lies very much in 'following in the footsteps' of others. Similarly, in Myerhoff's classic account of the peyote hunt in north central Mexico, the hunt draws its meaning both from the fact that it is collectively experienced by a group of people (not all copresent), and by the ways in which it is enmeshed in a larger cultural pattern [41].

Our concern here with collective experience can be contrasted with two common views in the information technology literature, the individual and the collaborative. The individual view, in HCI and elsewhere, focuses on the actions and experiences of people as solitary actors and as independent decision-makers. The collaborative view, in CSCW and elsewhere, pays attention to the ways in which the coordinated activities of multiple individuals produce larger-scale effects. However, this collaborative view of the social - as a multiplicity of individuals - often neglects a sense of the collective as a whole. Thinking of collective experience in terms of a multiplicity of individuals fails to see the forest for the trees. We want, instead, to be able to talk about collective experience; intersubjectively negotiated, individually incorporated, only more or less shared, and yet a common lens through which everyday experience can be made sense of. Within the CSCW literature, the notion of "community of practice" perhaps best approaches this, by placing the locus attention outside of the individuals but yet making this shared understanding foundational to meaning and interaction.

\section{Spatiality in Practice}

A recent research project that might shed some light on these directions was one that focused on cosmopolitans and their social practices The study of cosmopolitans took over a year and a half. We studied 54 people between the ages of 22 and 35 in London, Tokyo, LA, Belo Horizonte and Tallinn. We chose to look at young professionals, many in fairly freelance or autonomous employment situations. As is common in ethnographic work, we selected participants for theoretical interest and for trust relationships with the researchers rather than to serve as a statistical sample. We expected (and found) this group to be "tech savvy," mobile, and confronted with novel challenges as they adapted to a new life stage. We studied them as they went about their lives in the city. The common characteristic of the participants was a sense of cosmopolitanism. Cosmopolitanism was a reflection upon globalization from an aesthetic and moral perspective. We also sought, with some skepticism, to assess the notion that major urban areas, like London or Tokyo actually formed a coherent category - that they were essentially a single, distributed place, despite the apparent differences between urban areas. In particular, we paid close attention to objects people used to create their home space and what people carried with them to structure encounters in the urban environment. We examined how, when, and why things were used, and how it reflected who they were and wanted to be, as well as how it reflected the character, realities, and potential of the encompassing urban area. We observed the environments through which our participants traveled, shopped, worked, and 
recreated, and analyzed our participants' attitudes toward them, whether of fear, trust, engagement, disengagement, resignation, delight, or some combination. Our goal was to understand in detail how some residents of each of the urban areas practiced space making in the loose sense. We will highlight just a couple of participants as examples.

Jen was born in Australia, studied film in Cuba, worked for a major studio in LA and was a commercial and independent filmmaker when we caught up with her in London. Her flat in London was filled with a combination of IKEA and Italian designed furniture. She often commutes on her Vespa, listening to music on her iPod. She had acquired playlists from friends around London but also from friends in Adelaide, Sydney, and LA but also friends in Barcelona, NYC, Miami and Singapore. She often stops for food at an Italian deli for food on her way home. She frequents three coffee shops for her morning coffee, one by her home, one by her office and a Portuguese coffee shop not far from her house (usually the weekend coffeeshop). She drinks cappuccinos in the morning and either espressos or Americanos in the afternoon. She has made friends with the two coffeeshop owners; one of whom came from Australia and the other a boyfriend of a friend in the film school. Each of the coffeeshops provides a place for her to connect to the Internet via WiFi. She reads news from Sydney and works through her e-mail. She is able to move through the city with relative ease, bumping into friends and colleagues from advertising and media businesses. During our month long study with her, she traveled to Spain, Greece, and Morocco. On one 4-day trip to Madrid she gladly told us how she only took the clothes on her back and the bag she carries with her. She was able to stay in a French film friend's flat in Fez that was "just like home." Like most participants, she planned on being in the same life but different city in five years. She easily moves from place to place among friends and colleagues who suggest or offer places to stay, and guide her to the places with "good" food.

Angela was born outside Belo Horizonte. She studied design in Sao Paulo, then London. Her first job was in Barcelona. She later started up a design firm back in Belo. She had renovated her flat in a modern design with a combination of (ultra-) modern furniture. She routinely carried her mobile phone, iPod and wallet with her. Unlike others we studied, she had a laptop at work and one at home but didn't carry them between places. She has a coffee shop she goes to in the morning near home; she likes a coffee-milk for breakfast. She has felt at home where ever she goes. She seeks out places that are like all the other places she has been, regardless of where they are.

Mark lives in Tokyo. He has a 3500sq foot house in Roppongi that is supplied by the financial investment firm he works for. He has two other roommates at the house. The house is decorated just like the flats he had in London and Singapore. He goes to the ATM and withdraws his Yen using English. He has his coffee at a Starbucks, where he continuously monitors markets in London and NY on his smart phone. $\mathrm{He}$ meets up with other American investment bankers on Friday for drinks. On his way anywhere around town, you can see him on the train with a National Geographic and listens to his iPod. He travels with other advisors from around Asia down to Thailand to buy his clothes and take a little time off.

What we can see in these three examples, which are really representative of our other participants, was the way of taking a very local urban area and making it a particular kind of space. The cosmopolitans individually act and collective enact a 
particular spatial meaning through practice. Further, the examples point a number of mobilities in place. Though these have been stories of privileged technological mobility, it is clear that there are many not incorporated into the technologies. Just one example would be the lack of ATMs in Tokyo that offer Portuguese language interfaces for the many migrants who work there. While Angela can choose to visit any of the upscale Italian restaurants in the city or connect to the Internet at one of her cafes within walking distance of her house, her maid rides a bus for an hour to get to work with only other riders or an occasional newspaper as an information source. Angela, Mark and Jen are offered choices by our technologies, they are given agency and are accommodated by the technologies. The people who surround them, however, often are not. The processes of making space a place through practice are the same, while an advantage to the defining the place are given over to those with more technologies designed to meet their needs.

\section{Challenging Technical Practice}

Our goal, here, is not to provide detailed guidelines for the design of specific urban computing technologies. Rather, we have tried to set out an alternative perspective on what urban computing can do and can be. This perspective is deeply consequential for design practice, although its consequences lie largely in the kinds of questions that might motivate design, in the analytic perspectives that support pre-design exploration, and in the topics that might be thought of as relevant to design practice.

In line with the conference theme, we are particularly concerned with socially responsible design, and so with an approach to design that is both inclusive and progressive. To that end, our criticisms of much (certainly not all) of conventional urban applications of ubiquitous computing are that, first, they construe the city as a site for consumption, organizing it in terms of available resources; second, that they reflect only very narrowly the breadth of urban experience, focusing on particular social groups (generally young and affluent); third, that they focus on individual experience and interaction, rather than helping people connect and respond to the larger cultural patterns and urban flows within which they are enmeshed.

We see considerable opportunity for an elaboration of the urban computing agenda that takes these considerations seriously, and our goal here has been to provide a framework with which designers can begin to engage with the issues of diversity and agency in urban experience, that is an approach that is based in cultural mobilities.

For instance, undersound [5] goes beyond instrumental accounts of urban space to create an experience designed to reveal both the texture of urban life (as reflected by the links between urban space and musical genres) and the patterns of movement that characterize city living. Using the London Underground as an example, undersound creates an infrastructure in which music moves around the city through the public transportation system. Its design is based on the idea, first, that regions of the city have their own characters depending on local population groupings that can in turn shape locally-produced music; for instance, the music that emerges in one part of the city may reflect the ethnic origins of the local population. However, these must be encountered through the flows of people through the city, and the ways in which those intertwine. The system is designed to provide people with an alternative "window" 
onto urban life, and uses music as a means to reflect the diversity of urban living and its continual reconfigurations.

More broadly, the themes of diversity - a recognition and manifestation of the many different experiences of the city available to groups of different ages, economic conditions, ethnic identities, etc. - and agency - the active production of urban living rather than consumption and constraint - offer opportunities to reconsider the goals and methods of urban computing.

\section{Conclusion}

Mobility is firmly in view for HCI researchers these days, with a particular emphasis on urban environments. However, the interpretation of mobility on offer is a limited one. Mobility is considered simply as translation in a fixed spatial manifold, and the problems of a mobile subject. We have argued here for a cultural view of mobility (or mobilities). In this cultural view, we pay attention to the meaning of forms of mobility and how space and movement act as a site for the production of social and cultural meaning. To the extent that technology is always involved in the production of spatial realities, then technology is also involved in these cultural patterns, making them important for designers and analysts. At the same time, this also turns our attention back towards the social responsibilities of designers and HCI practitioners. As we have shown, the cultural perspective emphasizes that there is no one, simple mobility. There are many mobilities, and many collectives, whose view of mobility is shaped by more than simply an instrumental account of movement from A to B. A cultural view requires that we acknowledge and grapple with this diversity. In turn, this opens our eyes to a range of otherwise underrepresented groups within design.

We have suggested that we need to take diversity and agency as central aspects of a socially-responsible approach to mobile computing. This approach can also help connect current research in HCI and ubiquitous computing to contemporary work in human and social geography, providing a new foundation for design.

\section{Acknowledgements}

Johanna Brewer, Eric Kabisch, Amanda Williams, and our colleagues in Intel's People and Practices Research group made significant contributions to our work, as did those people who kindly gave of their time and insight in our fieldwork. This work was support in part by the National Science Foundation under awards 0133749 , 0205724, 0326105, 0527729, and 0524033

\section{References}

1. Agar, J.: The Government Machine: A Revolutionary History of the Computer. MIT Press, Cambridge (2003)

2. Agre, P.: Changing Places: Contexts of Awareness in Computing. Human-Computer Interaction 16(2-4), 177-192 (2001) 
3. Barkhuus, L., Chalmers, M., Tennent, P., Hall, M., Bell, M., Sherwood, S., Brown, B.: Picking Pockets on the Lawn: The Development of Tactics and Strategies in a Mobile Game. In: Proc. Intl. Conf. Ubiquitous Computing Ubicomp 2005 (Tokyo, Japan), Springer, Heidelberg (2005)

4. Basso, K.: Wisdom Sits in Places: Landscape and Language Among the Western Apache. University of New Mexico Press, Albuquerque, NM (1996)

5. Bassoli, A., Moore, J., Agamanolis, S.: TunA: Socialising Music Sharing on the Move. In: O'Hara, Brown (eds.) Consuming Music Together: Social and Collaborative Aspects of Music Consumption Technologies, Springer, Heidelberg (2006)

6. Bassoli, A., Brewer, J., Martin, K., Dourish, P., Mainwaring, S.: Underground Aesthetics: Rethinking Urban Computing.Technical Report LUCI-2007-002, Laboratory for Ubiquitous Computing and Interaction, University of California, Irvine, CA (2007)

7. Bell, M., Chalmers, M., Barkhuus, L., Hall, M., Sherwood, S., Tennent, P., Brown, B., Rowland, D., Benford, S., Capra, M., Hampshire, A.: Interweaving Mobile Games with Everyday Life. In: Proc. ACM Conf. Human Factors in Computing Systems CHI 2006, Montreal, CA, ACM, New York (2006)

8. Benford, S., Crabtree, A., Flintham, M., Drozd, A., Anastasi, R., Paxton, M., Tandavanitj, N., Adams, M., Row-Farr, J.: Can you see me now? ACM Trans. Comput.-Hum. Interact. 13(1), 100-133 (2006)

9. Brewer, J., Nguyen, D.: Who Rides the Bus? Alternative Mobility in Orange County. University of California, Irvine (2006)

10. Brown, B., Chalmers, M., Bell, M., MacColl, I., Hall, M., Rudman, P.: Sharing the Square. In: Proc. European Conf. Computer-Supported Cooperative Work ECSCW 2005, Paris, France, Springer, Heidelberg (2005)

11. Brown, B., MacColl, I., Chalmers, M., Galani, A., Randall, C., Steed, A.: Lessons from the Lighthouse: Collaboration in a Shared Mixed Reality System. In: Proc. ACM Conf. Human Factors in Computing Systems CHI 2003, Ft Lauderdale, FL, pp. 577-585. ACM, New York (2003)

12. Burrell, J., Gay, G., Kubo, K., Farina, N.: Context-Aware Computing: A Test Case. In: Borriello, G., Holmquist, L.E. (eds.) UbiComp 2002. LNCS, vol. 2498, Springer, Heidelberg (2002)

13. Cheverst, K., Davies, N., Mitchell, K., Friday, A.: Experiences of Developing and Deploying a Context-aware Tourist Guide. In: Proc. ACM Conf. Mobile Computing and Networking Mobicom 2000, Boston, MA, pp. 20-31. ACM, New York (2000)

14. De Certeau, M.: The Practice of Everyday Life. University of California Press (1984)

15. Debord, G.: The Society of the Spectacle (1967)

16. Dey, A., Salber, D., Abowd, G., Futakawa, M.: The Conference Assistant: Combining Context-awareness with Wearable Computing. In: Proc. Third Intl. Symposium on Wearable Computing, San Francisco, CA, pp. 21-28 (1999)

17. Duruz, J.: Eating at the Borders: Culinary Journeys. Environment and Planning D: Society and Space 23, 51-69 (2005)

18. Foucault, M.: Of Other Spaces. Diacritics 16, 22-27 (1986)

19. Garrioch, D.: Sounds of the City: The Soundscape of Early Modern European Towns. Urban History 30(1), 5-25 (2003)

20. Gaye, L., Mazé, R., Holmquist, L.E.: Sonic City: the urban environment as a musical interface. In: Proceedings of the 2003 Conference on New interfaces For Musical Expression (Montreal, Quebec, Canada, May 22 - 24, 2003) New Interfaces For Musical Expression, pp. 109-115. National University of Singapore, Singapore (2003) 
21. Graham, S.: Software-Sorted Geographies. Progress in Human Geography 29, 562-580 (2005)

22. Grinter, R., Aoki, P., Hurst, A., Szymanski, M., Thornton, J., Woodruff, A.: Revisiting the Visit: Understanding How Technology Can Shape the Museum Visit. In: Proc. ACM Conf. on Computer Supported Cooperative Work (New Orleans, LA), pp. 146-155. ACM, New York (2002)

23. Ho, J., Intille, S.: Using Context-aware Computing to Reduce the Perceived Burden of Interruptions from Mobile Devices. In: Proc. ACM Conf. Human Factors in Computing Systems CHI 2005 (Portland, OR), pp. 909-918. ACM, New York (2005)

24. Isaacs, E., Walendowski, A., Ranganthan, D.: Hubbub: A Sound-enhanced Mobile Instant Messenger that Supports Awareness and Opportunistic Interactions. In: Proc. ACM Conf. Human Factors in Computing Systems CHI 2001 (Minneapolis, MN), pp. 179-186. ACM, New York (2002)

25. Kelleher, W.: The Troubles in Ballybogoin: Memory and Identity in Northern Ireland. University of Michigan Press, Ann Arbor, MI (2003)

26. Lamming, M., Eldridge, M., Flynn, M., Jones, C., Pendlebury, D.: Satchel: Providing Access to Any Document, Any Time, Anywhere. ACM Trans. Computer-Human Interaction 7(3), 322-352 (2000)

27. McCullough, M.: On Digital Ground: Architecture, Pervasive Computing, and Environmental Knowing. MIT Press, Cambridge (2003)

28. le Marcis, F.: The Suffering Body of the City. Public Culture 16(3), 453-477 (2004)

29. Massey, D.: Power-geometry and a Progressive Sense of Place. In: Bird, Curtis, Putnam, Robertson, Tickner (eds.) Mapping the Futures: Local Cultures, Global Change, Routledge, London (1993)

30. Munn, N.: Excluded Spaces: The Figure in the Australian Aboriginal Landscape. Critical Inquiry 22(3), 446-465 (1996)

31. Myerhoff, B.: Peyote Hunt: The Sacred Journey of the Huichol Indians. Cornell, Ithaca, NY (1976)

32. Reid, J., Hull, K., Cater, K., Fleuriot, C.: Magic Moments in Situated Mediascapes. In: Proc. ACM SIGCHI International Conference on Advances in Computer Entertainment Technology ACE 2005 (2005)

33. Russell, D.M., Gossweiler, R.: On the Design of Personal \& Communal Large Information Scale Appliances. In: Abowd, G.D., Brumitt, B., Shafer, S. (eds.) Ubicomp 2001. LNCS, vol. 2201, pp. 354-361. Springer, Heidelberg (2001)

34. Spradley, J.: You Owe Yourself a Drunk: An Ethnography of Urban Nomads. Waveland Press, Prospect Heights, IL (1970)

35. Thrift, N., French, S.: The Automatic Production of Space. Trans. Institute of British Geographers 27(3), 309-335 (2002)

36. Vaneigem, R.: The Revolution of Everyday Life. Paris: Gallimand (1967) 